\title{
Epidemiology of injuries at the Australian 24 hour mountain bike championships
}

\author{
Nicholas B Taylor ${ }^{1}$ MBBS and Jamie Ranse ${ }^{2}$ MCritCarNurs \\ Affiliation: \\ 1: Staff Specialist in Emergency Medicine, Emergency Department, Canberra Hospital, Australian Capital Territory, \\ Australia \\ 2: Assistant Professor, Faculty of Health, University of Canberra, Australian Capital Territory, Australia
}

\section{ABSTRACT}

\section{Introduction}

To describe injury type and frequency, and the factors influencing these, in endurance mountain bike riders.

\section{Methods}

This study used a cross-sectional retrospective audit of patient report forms, prospective meteorological information and race data over an eight-year period. The Australian twenty-four hour mountain bike championships is held annually in Canberra, Australia. All riders who presented to a first aid station for treatment during the race from 2000-2007, were included. Studied factors influencing injury were race time, ambient temperature and rider gender. Studied outcome measures were injury frequency, location, type and management.

\section{Results}

Of the 14,777 riders over the eight years, 596 required first aid treatment for injuries $(4.03 \%)$, the majority for minor injuries to extremities. Only $0.25 \%$ of riders were referred to hospital, $0.06 \%$ by ambulance. The injury incidence was $8.4 / 1000$ bike hours with a race-ending presentation (a patient referred to hospital) incidence of $0.5 / 1000$ bike hours. Patient presentation rates were highest in the first eight hours of a race. Higher average temperatures per year were associated with a greater risk of injury. Females were more likely to be injured.

\section{Conclusion}

This mountain bike competition was safe with minor injuries to extremities predominating and low referral rates to hospital. Higher injury rates should be anticipated in hotter weather and during the first third of the race. The first aid service organisation provided adequate clinical care at this event.

\section{Keywords}

athletic injuries, epidemiological factors, Australia, off road cycling, mountain biking events, endurance

\section{INTRODUCTION}

Off-road cycling, commonly known as mountain biking, has increased in popularity, both in recreational and competitive forms. In Australia 750,000 adult bicycles were sold in $2006,70 \%$ of which were mountain bikes (1). Participation in competitive mountain biking events is increasing
$(2,3)$, as is the membership of mountain bike associations (Personal correspondence with $\mathrm{Mr}$ Tony Scott, Executive Officer, Mountain Bike Australia, March 2008). Mountain bike competitions run year-round across the globe, from local events to elite competitions including the Olympics. To date, most studies on mountain bike injury type and frequency have originated 
from North America $(4,5,6,7,8,9,10,11)$ Europe $(12,13,14)$, and New Zealand (15) for mixed discipline (downhill, cross country, other) events. There have been no previous studies evaluating injuries at endurance mountain biking events, which have become increasingly popular worldwide in recent years. There is also a paucity of Australian literature regarding mountain biking injuries.

The rate of injury in mountain bike competition participants has been reported as between $0.4 \%$ and $0.6 \%(10,12)$ or between 1 and 3.4 injuries per 1000 bike hours ridden $(9,12)$. These injuries were in mixed discipline mountain bike events and were only recorded if they were race-ending. Approximately $50 \%$ of competitive mountain bike riders will sustain at least one serious injury per year (4). Minor injuries $(4,5,10,12,14)$ of the extremities $(4,5,11,14)$ are the most common presentations sustained at mountain biking events. Severe injuries have been reported at approximately $4 \%$ (7) and include cervical spine fractures (14), haemopneumothorax (14) and blunt abdominal trauma (13). Between $4.4 \%$ and $10 \%$ of participants are referred to an emergency department, $(4,7,12)$ the majority with orthopaedic injuries (8). Of those emergency department admissions, $66 \%$ required surgical intervention (8). It has been suggested that presentations related to mountain bike competitions in small jurisdictions can have a significant workload impact on healthcare providers and facilities (16). Of those injured, young males are most commonly represented, however females may have a higher propensity for injury $(6,9)$.

Competitive spirit, speed, slippery surfaces, poor rider judgment and downhill racing have been identified as additional risk factors for injury $(11,12,13)$. This is the first study to focus on endurance racing and the only Australian study recording mountain bike injuries.

\section{METHODS}

\section{Setting and Subjects}

This research was set at the world's largest twenty-four hour mountain bike race, the annual Australian championships. The race was hosted by the Canberra Off Road Cycling Club, held during October (Spring) in Canberra, Australia. Each year, the race commenced at midday on Saturday and was completed after midday on Sunday. This event had a large participation with a wide cross section of riders, including both novice recreational and elite professional riders. The race involved multi-lap cross country style endurance racing, over varied terrain which combined single track, double track and dirt road, with each lap undulating over 150 vertical metres for a distance of 12-21 kilometres.

\section{Data Collection}

We obtained information from all patient presentations during the event, at St John Ambulance Australia first aid posts between 2000 and 2007. St John Ambulance Australia first aid volunteers use a standardised patient report form to record patient demographics, observations, injury location, injury type, clinical management and patient disposition. All presentations were coded using a data dictionary adapted from St John Ambulance Australia (St John Ambulance Australia. 2005. Event and Emergency First Aid Minimum Data Set (unpublished)) and the Australian Institute of Health and Welfare (17). The Canberra Off Road Cycling Club used a computerized system to record rider demographics, rider race length and timing data. We obtained this information from the Canberra Off Road Cycling Club's race statistician (Personal correspondence with Mr Russell Baker, official race statistician, Australian twenty-four hour mountain bike championships, March 2008). Additionally, hourly meteorological data for temperature and rainfall was obtained from the Australian Government, Bureau of Meteorology (18).

\section{Data Analysis}

SPSS, version 14.0 (SPSS Inc, Chicago, III, USA) was used to calculate simple descriptive statistics for injury type and frequency, an $\chi^{2}$ test was used to calculate gender differences and a Cox multivariate regression analysis was used as a survival model to determine the risk of injury over the race period versus meteorological factors. Rate ratios were determined with a $95 \%$ confidence interval and a significance of $5 \%$.

\section{Ethics}

This research was approved by the St John Ambulance Australia Human Research Ethics Committee. All patient information was collected and used in a de-identifying manner.

\section{RESULTS}

There was similarity of entrant demographic between the studied years of the race. Males made up $87.5 \%(85.9-90.0)(12,930 / 14,777)$ of the entrants and females $12.5 \%(10.0-14.1)$ $(1,847 / 14,777)$, see Figure 1. The proportion of females presenting for treatment $(105 / 1,847=5.68 \%(4.69-6.86)$ was significantly higher than males $(491 / 12,930=3.8 \%$, $(3.48-4.15)$ $(p=0.0001)$. The average distance ridden per team was $302.8 \mathrm{~km}$ (74km per rider), and was similar from year to year, suggesting comparable skill mix and track characteristics.

Over the eight years in which data was collected, $675(4.6 \%)$ of the 14,777 riders presented to a St John Ambulance Australia first aid posts for 
treatment. $596(88.3 \%)$ of presentations were injuries, $67(9.9 \%)$ were illness, and $12(1.8 \%)$ were environmental related. This proportion was similar across all years. Over $65 \%$ of the medical presentations were for asthma or headache.

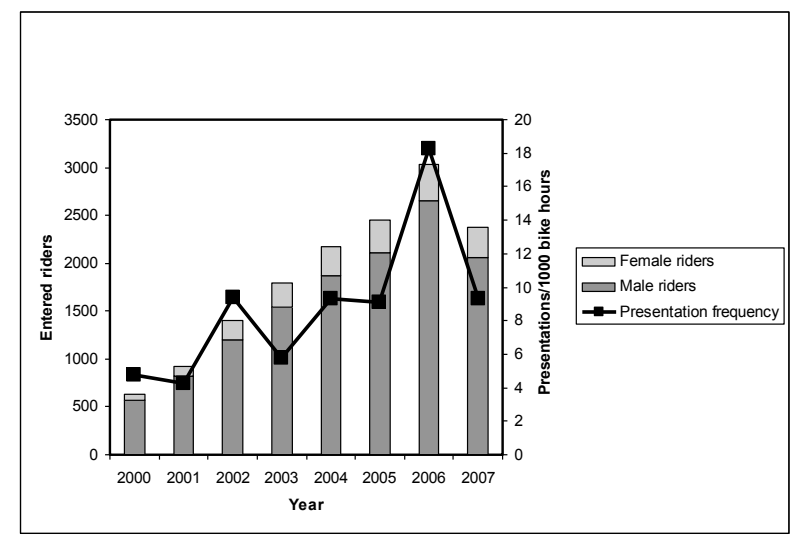

Figure 1: Riders entered and injury presentation incidences per year

Of particular note is that superficial injuries (table 1 ) and injuries involving an extremity (table 2) predominated. Eye injuries constituted $6 \%$ of all injuries. Injuries such as suspected fractures or dislocations $(2.3 \%)$ and closed head injuries (5\%) were minimal. Only $27 / 596(4.5 \%)$ of all injury presentations, or $0.18 \%$ of all riders, were referred to hospital (a race-ending injury). Serious presentations were uncommon, with only $(5 / 596)$ $0.8 \%$ of all injury presentations, or $0.03 \%$ of all riders, transported to hospital by Ambulance.

\begin{tabular}{lll} 
Injury type & $\boldsymbol{f}$ & \% \\
\hline Abrasion & 225 & 37.8 \\
Multiple injuries & 89 & 14.9 \\
Sprain or strain & 66 & 11.1 \\
Superficial laceration & 58 & 9.7 \\
Open wound & 37 & 6.2 \\
Foreign body in external eye & 31 & 5.2 \\
Other minor wound & 29 & 4.9 \\
Review of injury & 22 & 3.7 \\
Blister & 10 & 1.7 \\
Fracture & 9 & 1.5 \\
Eye injury & 5 & 0.8 \\
Foreign body in soft tissue & 5 & 0.8 \\
Crushing Injury & 3 & 0.5 \\
Intracranial injury (eg & 3 & \\
concussion) & 2 & 0.5 \\
Dislocation & 2 & 0.3 \\
Foreign body in ear canal & 0.3 \\
Total & 596 & 100 \\
\hline Table 1: Injury presentation type & &
\end{tabular}

The overall injury incidence was $8.4 / 1000$ bike hours with a race-ending presentation (referred to hospital) incidence of $0.5 / 1000$ bike hours.

Approximately half of the presentations occurred in the first eight hour period of the race (day/evening) when compared to the second (evening/night) or third (night/day) periods.

\begin{tabular}{lll} 
Injury location & $\boldsymbol{f}$ & \% \\
\hline Limb & 353 & 59.2 \\
Multiple & 164 & 27.5 \\
Head, face and neck & 60 & 10.1 \\
Truck & 16 & 2.7 \\
Back & 3 & 0.5 \\
Total & 595 & 100 \\
\hline Table 2: Injury location & &
\end{tabular}

Figure 2 illustrates the cumulative presentation rate over the race period, from the start of the race to two hours following completion of the race. After twenty-six hours the cumulative presentation rate was $15.6 \%$. This shows the risk of a single rider presenting for first aid, should they have ridden for the entire race. The actual risk per rider was lower due to riders forming teams (average team size was four riders). For the first eight hours of a race there was generally a steady rate of presentations ( $8.2 \%$ cumulative at 8 hours). From the eighth to eighteenth hour the rate of presentations slowed (cumulative $11.1 \%$ at 18 hours). The presentation rate increased again for the latter third of the race.

Minimal rainfall occurred during the races and was not investigated further. Air temperature and year, however, influenced presentation rates. In terms of year, the regression model showed that years varied significantly in their risk of an injury presentation (Chi square $=1254.1, \mathrm{df}=8, \mathrm{p}$ $<0.0001)$. Higher average ambient air temperature was associated with a higher risk of presentation (see Table 3).

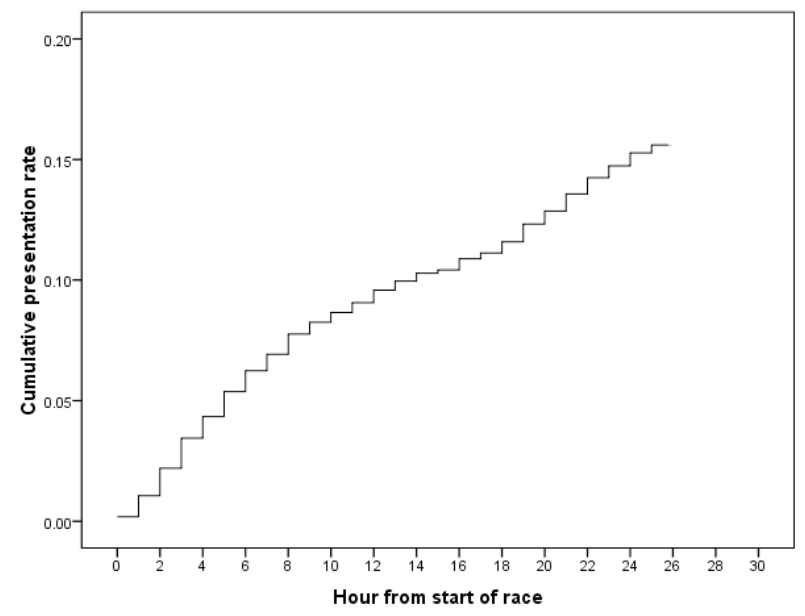

Figure 2: Cox Regression analysis of injury risk 


\begin{tabular}{|c|c|c|c|c|c|}
\hline Year & $\begin{array}{l}\text { Injury } \\
\text { rate }\end{array}$ & $\begin{array}{l}\text { Avg } \\
\text { Temp } \\
\left({ }^{\circ} \mathrm{C}\right)\end{array}$ & HR & $\begin{array}{l}95 \% \\
\mathrm{Cl}\end{array}$ & $p$ value \\
\hline 2000 & 9.9 & 19.1 & Ref & Ref & Ref \\
\hline 2005 & 12.8 & 12.7 & 0.119 & $\begin{array}{l}0.065 \\
0.217\end{array}$ & $<0.0001^{*}$ \\
\hline 2003 & 11.3 & 13.8 & 0.187 & $\begin{array}{l}0.102, \\
0.345\end{array}$ & $<0.0001^{*}$ \\
\hline 2001 & 9.4 & 18.3 & 0.539 & $\begin{array}{l}0.271 \\
1.071\end{array}$ & 0.078 \\
\hline 2007 & 20.4 & 19.5 & 1.563 & $\begin{array}{l}0.891 \\
2.742\end{array}$ & 0.119 \\
\hline 2002 & 19.1 & 18.3 & 1.723 & $\begin{array}{l}0.967 \\
3.070\end{array}$ & 0.065 \\
\hline 2004 & 15.2 & 20.4 & 1.850 & $\begin{array}{l}1.047 \\
3.269\end{array}$ & $0.034^{*}$ \\
\hline 2006 & 20.1 & 22.5 & 2.447 & $\begin{array}{l}1.409 \\
4.248\end{array}$ & $0.001^{*}$ \\
\hline
\end{tabular}

Table 3: Least to highest relative risk from multivariate regression

† injuries per 1000 bike hours ridden

* significant at $<0.05$

\section{DISCUSSION}

This is the first study to evaluate endurance mountain biking injuries and the first large Australian study of mountain biking injuries. In agreement with previous studies, females were more likely to present with injuries than their male counterparts $(6,7)$. Injury mechanism data to explore reasons behind this finding were unobtainable, and should be considered prospectively for future research.

Similar to the results of prior studies from multidiscipline elite events, the majority of mountain bike injuries were soft tissue wounds of the extremities $(4,5,11,12,14)$. Gloves have near universal uptake amongst the mountain bike fraternity and should be encouraged to be worn as a measure to reduce injury. Similarly, future development of lightweight, breathable, abrasion resistant clothing may prevent many soft tissue extremity injuries.

The time period of a race and the average temperature of the race influenced the patient presentation rate. The risk of presenting with an injury varied over the course of a race, with the first eight hours of a race having the greatest risk. This may be due to a combination of factors requiring further investigation, such as track congestion and competitive spirit. The presentation rate increased between years when the average ambient air temperatures were higher. Temperature effect may be a particular feature of endurance races, given the potential role of fatigue and dehydration in decreasing rider strength and concentration. Clinical care providers and event organisers should be aware of these factors and implement strategies to manage peak patient presentations.

Endurance mountain biking at the Australian twenty-four hour championships appears to be safe, with generally low injury frequencies, particularly serious injuries, as reinforced by the very low number of referrals to hospital. The rate of race-ending injury at this endurance event was one half to one seventh of that reported previously at multidiscipline events.

Helmet use is mandatory both for competition and recreational cycling in Australia. This, combined with the relatively lower speeds of endurance racing compared to other mountain biking disciplines (particularly downhill), may explain this very low serious injury frequency. The wide spread of rider skill level and the varied track characteristics at this event allows for the extrapolation of this data to approximate the injury frequency of the Australian recreational mountain biking community. Extrapolation of this data to other endurance races requires more caution, due to the organising body having a focus on, and reputation for, safety at this event.

The low hospital referral rate would be unlikely to significantly alter the workload of a nearby tertiary hospital emergency department. However, depending on an event's location and first aid service capacity, a regional or rural health service could easily be pressured by a large mountain biking event (14). A first aid service provider such as St John Ambulance was sufficient clinical coverage for this event, with the majority of injuries not requiring a medical officer for management.

A number of factors may influence patient presentation rates that were not explored during this study. Data was not collected regarding the skill level of the injured riders and this may be a significant factor in injury patterns. Data was also not collected regarding individual rider times and due to ethical consideration, no correlation was possible with the injured rider and their time on the bike. Additionally, we were unable to accurately determine the effect of congestion on presentation rates because of a lack of adequate rider density data. Improved race recording technology, with an ability to determine hourly participant numbers on the track, would assist in determining the effect of congestion on presentation rates.

\section{CONCLUSION}

The Australian twenty-four hour endurance mountain bike championships are a generally safe event. Endurance mountain biking has lower raceending injury rates when compared to other mountain bike disciplines, with the majority of injuries being of the minor extremities. Injury rates were increased in the first part of the race and by higher air temperatures. First aid service providers were sufficient for clinical care at this event. 


\section{CONFLICT OF INTEREST}

The authors declare they have no conflict of interest.

\section{ACKNOWLEDGEMENTS}

The authors wish to acknowledge the research grant provided by St John Ambulance Australia that assisted in the completion of this research. The authors wish to thank Mr Russell Baker, Canberra Off Road Cyclists race statistician; Associate Professor Drew B Richardson, Australian National University Clinical School; Dr Bruce Shadbolt, Australian National University, Epidemiologist and Chris Ward, CEO St John Ambulance Australia ACT.

\section{Funding}

The authors received the equivalent of $\$ 1,000$ USD from a St John Ambulance Australia competitive research grant to complete this research

\section{REFERENCES}

1. The Australian bicycle industry report 2006. edited Bradshaw, G. Retail cycle traders Australia website. Available from URL http://www.rcta.org.au. Accessed May 12 2009.

2. The Australian bicycle industry report 2004 . edited Bradshaw, G. Retail cycle traders Australia website. Available from URL http://www.rcta.org.au. Accessed May 12 2009.

3. The Australian bicycle industry report 2003. edited Bradshaw, G. Retail cycle traders Australia. Available from URL http://www.rcta.org.au. Accessed May 12 2009.

4. Chow TK, Bracker MD, Patrick K. Acute injuries from mountain biking. West $\mathrm{J}$ Med. 1993;159:145-148.

5. Pfeiffer RP. Off-road bicycle racing injuries-the NORBA Pro/Elite category. Care and prevention. Clin Sports Med. 1994;13:207218.

6. Kronisch RL, Pfeiffer RP, Chow TK, Hummel CB. Gender differences in acute mountain bike racing injuries. Clin J Sport Med. 2002;12:158-164.

7. Rivara FP, Thompson DC, Thompson RS, Rebolledo D. Injuries involving off-road cycling. J Fam Pract. 1997;44:481-485.

8. Kim PT, Jangra D, Ritchie AH, et al. Mountain biking injuries requiring trauma center admission: a 10-year regional trauma system experience. J Trauma. 2006;60:312-318.
9. Kronisch RL, Pfeiffer RP, Chow TK. Acute injuries in cross-country and downhill off-road bicycle racing. Med Sci Sports Exerc. 1996;28:1351-1355.

10. Kronisch RLA, Chow TK,. Simon LM , Wong PF. Acute Injuries in Off-Road Bicycle Racing. Am J Sports Med. 1996;24:88-93.

11. Chow TK, Kronisch RL. Mechanisms of injury in competitive off-road bicycling. Wilderness Environ Med. 2002;13:27-30.

12. Gaulrapp H, Weber A, Rosemeyer B. Injuries in mountain biking. Knee Surg Sports Traumatol Arthrosc. 2001;9:48-53

13. Nehoda H, Hochleitner BW, Hourmont K, et al. Central liver hematomas caused by mountain-bike crashes. Injury. 2001;32:285287.

14. Jeys LM, Cribb G, Toms AD, Hay SM. Mountain biking injuries in rural England. $\mathrm{Br}$. J. Sports Med. 2001;35:197-199.

15. Rajapakse B, Horne G, Devane P. Forearm and wrist fractures in mountain bike riders. $\mathrm{N}$ Z Med J. 1996;26:147-148.

16. Carmont MR, Daynes R, Sedgwick DM. The impact of an extreme sports event on a district general hospital. Scott Med J. 2005;50:106108.

17. Australian Institute of Health and Welfare. 2003. Injury surveillance National Minimum Data Set. National Health Data Dictionary (version 12). AlHW Cat. No. HWI 57. Canberra: Australian Institute of Health and Welfare.

18. Australian Government. Bureau of Meteorology, Personal correspondence with NSW regional office, Climate Services Division, April 2008. Available via URL http://www.bom.gov.au 